\title{
Using Reading to Learn Pedagogy to Improve Chinese Writing among Ethnic Minority Students in Hong Kong: A Quasi-experimental Study
}

\author{
Xian Han Huang ${ }^{1,}$, Mark Shiu Kee Shum ${ }^{2}$, Chung Pui Tai ${ }^{1}$, Dan Shi ${ }^{3}$ \\ ${ }^{1}$ The Faculty of Education, The University of Hong Kong, Hong Kong, P. R. China \\ ${ }^{2}$ Centre for Advancement of Chinese Language Education and Research Within the Faculty of Education, The University of Hong Kong, Hong \\ Kong, P. R. China \\ ${ }^{3}$ School of English, University of Nottingham Ningbo China, Ningbo, P. R. China
}

\section{Email address:}

yxhhuang@hku.hk (Xian Han Huang), mskshum@hku.hk (Mark Shiu Kee Shum), cptai@hku.hk (Chung Pui Tai),

Dan.Shi@nottingham.edu.cn (Dan Shi)

${ }^{*}$ Corresponding author

\section{To cite this article:}

Xian Han Huang, Mark Shiu Kee Shum, Chung Pui Tai, Dan Shi. Using Reading to Learn Pedagogy to Improve Chinese Writing among Ethnic Minority Students in Hong Kong: A Quasi-experimental Study. International Journal of Language and Linguistics.

Vol. 7, No. 5, 2019, pp. 202-212. doi: 10.11648/j.ij11.20190705.14

Received: July 2, 2019; Accepted: August 3, 2019; Published: August 28, 2019

\begin{abstract}
Reading to Learn (R2L) is a widely used pedagogy in numerous countries. However, most studies on R2L pedagogy focused on teaching English as a second language. Chinese is a Sino-Tibetan language that adopts a nonalphabetical orthography, and only a few studies have discussed the application of R2L pedagogy in teaching Chinese as a second language. To fill this gap, a quasi-experimental study was adopted to explore the effectiveness of R2L pedagogy in improving the performance of ethnic minority students in Hong Kong in terms of Chinese composition. Four teachers and 103 students from two middle schools were invited to participate in the study, which lasted for three months. The hypothesized positive effects on increased student writing performance in the explanatory genre were demonstrated via empirical data. Moreover, R2L pedagogy improved the students' awareness of the importance of incorporating various stages and details when writing essays. Student participation considerably increased with additional support from peers and teachers. However, teachers encounter three challenges in implementing R2L pedagogy. First, they must possess a basic understanding of systemic functional linguistic theory and R2L pedagogy before designing the curriculum. Second, full participation might conflict with the limited teaching time during the implementation of R2L pedagogy. Third, teachers must deal with students' various learning needs due to the latter's diverse language levels and backgrounds. The practical implications of this study have also been discussed.
\end{abstract}

Keywords: Reading to Learn Pedagogy, Second Language Acquisition, Ethical Minority Students, Writing

\section{Introduction}

Systemic functional linguistics (SFL), also known as the pedagogy of the 'Sydney School' e.g., [1,2], considers language as a meaning-making system [3] and highlights the social functions of language [4]. Specifically, SFL discusses how particular language choices are made by writers to construct meaning and stresses how social contexts influence textual realisation. This theory advances the idea that language always has three meta-functions: the ideational meta-function for experiencing inner and outer worlds; the interpersonal meta-function for connecting ideas; and the textual meta-function for transforming the above two constructs into spoken or written texts [5]. These three meta-functions are always present, integrated in language and their realisation relies on the specific contexts in which language is produced. From the SFL approach, genre refers to 'a staged goal-oriented social process', and genre theory becomes 'an outline of how we use language to live' [3]. Inspired by SFL and genre theory, considerable research has been conducted to improve language teaching worldwide. e.g. [1, 6-18]. 


\subsection{Genre-Based Pedagogy}

Genre-based pedagogy aims to help students complete literacy tasks in schools and society which can be identified and categorised into a taxonomy of genres [19]. This pedagogy initially identifies the types of text (genre) within which students write. Then this pedagogy guides students through a stage-oriented process, allowing them to experience different levels of language, and supporting their reading and writing competencies via classroom activities that centre on selected texts $[20,21]$. Within the framework of genre-based pedagogy, the learner understands that a text stems from a certain social situation and is used by participants to further their objectives [22]. Specifically, Hyland [12] identified six advantages of genre-based pedagogy for effective learning. The first advantage is explicitness, which is a genre-based writing instruction offering a clear understanding of how target texts are structured and why they are written in a certain manner. Explicitness guides teachers and learners to achieve clear writing outcomes instead of relying on hit-or-miss inductive methods. The second advantage of genre-based pedagogy is that it can be systematic, focusing on a framework, language knowledge and the specific context in which a text is used. The third advantage of genre-based pedagogy is that it can be needs-based, highlighting the learning objectives and the content. This advantage stems from and echoes the authentic needs of learners. The fourth advantage is that this approach can be supportive, emphasising that a teacher may scaffold student learning with various teaching strategies and learning tasks. The fifth advantage is that it can be critical, which means that students may be encouraged to comment on and even challenge valued discourses. The sixth advantage of genre-based pedagogy is the capacity for consciousness-raising, which suggests that the teacher should be fully aware of the text and able to integrate it with effective teaching. In total, genre-based pedagogy stresses that the teacher should be clear about student needs and then address them with effective, systematic and explicit teaching strategies. Meanwhile, students need to understand that a text is a combination of linguistic resources which connects the self, others and situations, thus allowing us to construct, negotiate or even transform our understanding of society and ourselves.

\section{2. 'Reading to Learn'(R2L) Pedagogy}

Extending the principle of embedded literacy found in genre pedagogy, the 'Reading to Learn' (R2L) pedagogy, grounded in research on language and writing pedagogy, was initially designed for students in an indigenous community in central Australia who lacked support in English literacy [19] (see Figure 1). The R2L pedagogy guides students from reading to writing through the 'prepare - task - elaborate' cycle. In each cycle, several texts are provided for students to read and they become the basis for students learning how to write their own texts. The pedagogy includes nine sets of learning activities across three levels that are characterised by the explicitness in each stage of preparation, and by the connectedness from the elaboration of one task to the preparation for the next (see Table 1). These learning activities provide flexibility and rich possibilities in scaffolding to equip students with different abilities with the skills required for any particular learning task.

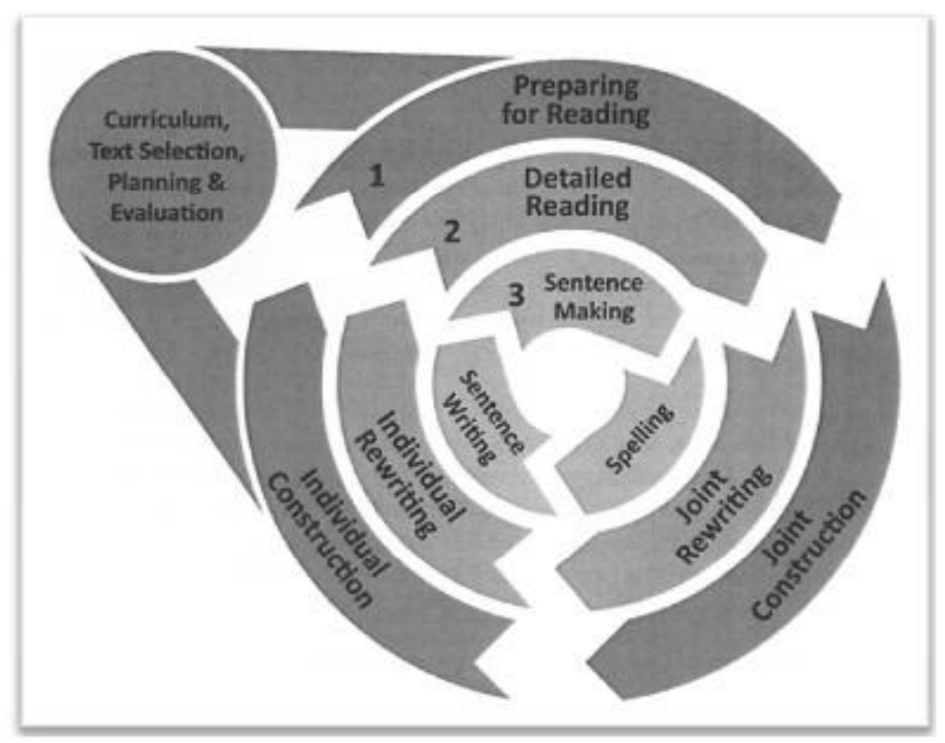

Figure 1. By D. Rose and J. R. Martin, 2012, Learning to write, reading to learn: Genre, knowledge and pedagogy in the Sydney school, p. 154.

Table 1. Nine sets of learning activities in 3 levels of scaffolding support.

\begin{tabular}{llll}
\hline Level 1 & Preparing for reading & Joint construction & Individual construction \\
Level 2 & Detailed reading & Joint rewriting & Individual rewriting \\
Level 3 & Sentence making & Character recognition & Sentence writing \\
\hline
\end{tabular}

By D. Rose and J. R. Martin, 2012, Learning to write, reading to learn: Genre, knowledge and pedagogy in the Sydney school. South Yorkshire: Equinox Publishing Ltd, p. 147. 
Specifically, the tasks at Level 1 are better suited to advanced learners because the activities focus on the structure of the text as a whole. Here, teachers help students to read and understand texts and to deconstruct model texts for writing during the step of preparing for reading. Next, students need to jointly and then individually construct new texts, similar to the one under analysis, while bringing forth all of the knowledge and skills learned in the previous stage. The following chart shows the flow of learning at this level (see Figure 2).

$$
\text { Level } 1 \quad \text { Preparing for reading } \longrightarrow \text { Joint construction } \longrightarrow \text { Individual construction }
$$

Figure 2. Learning flow for advanced learners.

For medium learners, teachers can descend to Level 2 for stronger support in the area of detailed comprehension. The focus at this level is to identify the patterns of meaning within and between sentences. Then, students attempt to jointly and individually rewrite the passages they learned before constructing a new passage (see Figure 3 ).

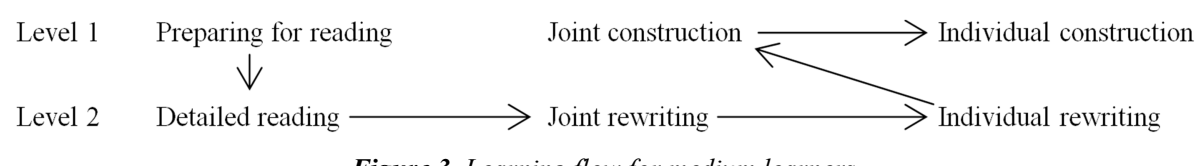

Figure 3. Learning flow for medium learners.

Level 3 is designed to cater to the needs of beginning learners and it stresses foundational skills in reading and writing, such as spelling and word choice. Based on the learning activities of Level 1 and Level 2, several sentences are selected from those detailed reading passages to serve as the basis for students' sentence-making activities (see Figure 4).

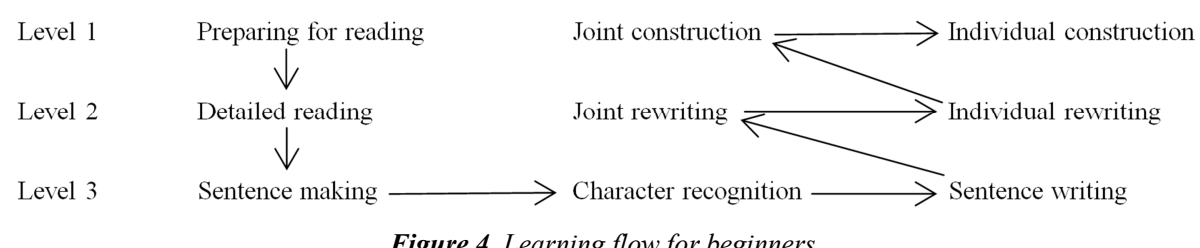

Figure 4. Learning flow for beginners.

Overall, with R2L, teachers can flexibly use various scaffolding teaching stratgies according to the student's backgrounds and level of language knowledge. Throughout the entire process, students are explicitly guided by their teachers to decode words, identify sentence meanings, infer connections across a text, interpret the social context of a text and then apply the acquired knowledge to their own writing [19].

To date, R2L has been widely used in many countries and districts. For example, McRae and colleagues found that R2L can effectively help Australian indigenous students raise their English level [23]. Acevedo demonstrated that R2L can lead to at least a $30 \%$ improvement in the writing development of Swedish students [24]. Rose reported positive feedback from teachers and students in Spain [25]. In addition, studies in the Asian context also found that R2L can help students increase their performance in learning English as a second language. e.g., [26, 27]. Most research on R2L has been conducted in the field of English as a second language. e.g., [6, 28-33], and this field is different than that of teaching and learning Chinese, a Sino-Tibetan language which adopts a non-alphabetical orthography (See Shum et al., 2016, 2018 for an exception [34, 35] ). To the author's best knowledge, few studies have discussed the challenges faced by teachers in conducting R2L in the Asian context. Therefore, this study was designed and implemented to fill this research gap by introducing the R2L model to improve the performance of writing Chinese among ethnic minority students in Hong Kong.

\subsection{Ethnic Minority Students in Hong Kong and Their Chinese Language Learning}

The R2L model was initiated in response to the educational needs of students in Australia who speak a language other than English in their family [25]. After the 1997 handover, Hong Kong similarly witnessed a growing need to support students from ethnic minority backgrounds who learn Chinese as an additional language. According to statistics, $61.1 \%$ of primary schools and $57.7 \%$ of secondary schools in Hong Kong have ethnic minority students of whom more than $80 \%$ are Pakistani, Nepali, Filipino and Indian [36]. Among these minorities, around $30 \%$ to $60 \%$ can speak Chinese and only approximately $15 \%$ to $35 \%$ can read and write in Chinese [37]. This represents a great challenge for Chinese teachers in Hong Kong.

In Hong Kong, most Chinese language teachers are trained to teach Chinese as a first language. They often lack awareness of, and fail to identify, the learning needs of ethnic minority students who learn Chinese as an additional language. Additionally, even though they realise the special needs of their students, these teachers lack the professional skill needed to re-design teaching content and to effectively tailor lesson plans to this group. Clearly, the student's poor language foundation and the conventional teaching methods negatively affect the acquisition of the Chinese language among ethnic minority students in Hong Kong [38, 39]. To address this issue, 
this study was designed to provide an alternative approach for improving Chinese writing among ethnic minority students in Hong Kong.

\subsection{Research Question and Hypotheses}

To explore the effectiveness of implementing R2L in teaching Chinese as an additional language, a quasi-experimental approach was adopted. As the first attempt to apply the R2L model to evaluate the Chinese writing of South Asian ethnic minority students, this study also aims to gain insight into the challenges faced by teachers when using R2L in their classrooms. Thus, the research questions of this study can be specified as below:

RQ 1: Does R2L help ethnic minority students improve their writing performance in Chinese?

RQ 2: What are the challenges for teachers as they implement R2L in the teaching of Chinese as an additional language?

To answer the first question, two hypotheses were constructed based on the literature review:

Hypothesis 1: The experimental and control groups demonstrate improved writing performance after three months of Chinese instruction.

Hypothesis 2: The writing performance of students from the experimental group outperforms that of their counterparts, indicating the effectiveness of the R2L pedagogy.

\section{Methodology}

\subsection{Setting and Participants}

This study was conducted in a direct subsidy scheme secondary school. In this school, over $80 \%$ of the students are South Asian students who are learning Chinese as a foreign language. The majority of academic subjects in this school, except for Chinese, are delivered in English. The school provides two types of Chinese curriculum for these South Asian students. One is Chinese as a foreign language (CFL), which suits students with low Chinese proficiency who can understand basic Chinese words and phrases and write several short sentences. The medium of instruction for their Chinese lessons is English. The other type of Chinese curriculum is immersion intermediate Chinese (IIC), which is tailored to students whose Chinese level is higher than that of the CFL students. A useful example is provided by form 2 IIC students. Their level of Chinese listening and speaking is similar to that of grade 4 or 5 Hong Kong students in primary school. That is to say, these students can basically express thoughts, ideas and opinions in Chinese. However, they are still struggling when it comes to reading and writing. The medium of instruction for IIC students is Chinese.

To explore the effects of R2L in teaching Chinese as a foreign language on both beginners and medium learners, this study invited two parallel classes from each cohort of the Chinese curricula, namely, two classes from the IIC cohort and two classes from the CFL cohort. A total of 115 non-Chinese speaking students and four teachers were invited to participate in this study. However, 12 students did not complete both the pre- and post-tests and at least one instructional model due to various personal reasons. These data were excluded, and a total of 103 students remained in the subsequent analysis.

Before conducting the experiment, the students in each cohort were randomly assigned to control and experimental groups. The student scores on the Chinese language tests of the previous academic year were also used to double check that the Chinese language ability between experimental and control groups was equivalent. After distribution, the researchers carried out pre-tests to measure the writing performance of students.

Among the 103 students participating in this study, there were 41 students and 62 students in the IIC and the CFL cohort, respectively. In the IIC cohort, $60 \%$ and $62 \%$ of students in the experimental and control groups, respectively, were female. In the CFL cohort, $40 \%$ and $53 \%$ of students in the experimental and control groups, respectively, were female. The mean age of the students was 15 years $(\mathrm{SD}=0.90$, range $=14$ to 18 years).

\subsection{R2L Pedagogy Treatment}

This research adopted a quasi-experimental pre-post-design to explore the effectiveness of the $\mathrm{R} 2 \mathrm{~L}$ pedagogy. To match the topics required in school for students in the IIC and CFL cohorts, researchers selected the factorial explanation genre to design the curriculum. Three and two instructional modules were conducted for the IIC and CFL cohorts, respectively. The topics of three instructional modules for IIC were East Asian Games, Eastern Customs and Culture and Religion, whereas the topics for CFL cohort were Chinese Food and Eastern Customs and Culture. Both cohorts used three months to complete the modules. Before conducting the experiment, consent was obtained from the school principals, teachers, students and parents.

For the experimental group, teachers prepared students for reading by teaching topic-related background information. The students' previous knowledge regarding the topic was stimulated by sharing experiences and group discussions. At the stage of detailed reading, the students perused a text under the direction of teacher and analysed keywords, such as new words and phrases, and they discussed the typical stages of the factorial explanation genre, which includes phenomenon identification, explanation sequence and conclusion. During this session, the teacher not only illustrated the context, analysing language and structure, but also explored the students' knowledge relative to the topic by asking literal, inferential and interpretative questions [19]. This approach helped the students to construct their own understanding of the topic and genre. Various exercises at both the individual and group level in word mastery, sentence understanding and the analysis of stages were used to strengthen the learning outcome. For the CFL cohort, the teacher used more intensive strategies and learning tasks which included character recognition, sentence making and sentence writing to provide a higher level of support for practising reading and writing skills. Then the students were 
grouped and asked to jointly construct some sentences or paragraphs in the text under the guidance of the teacher. This approach provided the students with an opportunity to explicitly communicate their understanding of the learning content and implement the imparted language knowledge in a relatively authentic context [19]. Afterwards, the students then co-wrote a composition. The theme of the composition was similar to the text that they had learned in class. For example, the co-construction task of the module of 'East Asian Games' was 'Sports day in our school'. Each student was asked to contribute at least one sentence to the draft. The students thought, communicated and negotiated with their peers during this co-construction. During this process, the teachers' directions or suggestions effectively scaffolded the learning and writing by highlighting stages and by emphasising key phrases and sentences. Through this process, the students' understanding of stages and language knowledge was further strengthened. Afterwards, each student was required to write an explanatory composition independently to consolidate and apply what they had learned in the Chinese lessons. During the entire session, the teacher could adapt the rhythm of teaching based on the acceptance level of the students. Both the IIC and CFL cohorts took three months to finish three and two instructional modules, respectively.

Two teachers were invited to study R2L pedagogy before teaching the students in experimental groups. Throughout the experiment, these teachers and researchers closely collaborated on curriculum design and implementation. All of the teaching content, instructional strategies and learning tasks were co-designed by the teachers and researchers according to R2L pedagogy. During the implementation, all of the experimental groups' lessons were observed by a research assistant who was a $\mathrm{PhD}$ candidate and was familiar with $\mathrm{R} 2 \mathrm{~L}$ pedagogy. After each lesson, the research assistant collected teacher feedback and discussed implementation with teachers to ensure that the teachers were able to apply R2L theory to classrooms in a dynamic and realistic manner. To assure the fidelity of implementing R2L, all of the lessons for the experimental groups were video-taped and checked by researchers each week. The researchers' evaluations covered four dimensions: instructional objective, teaching content, instructional strategy and assessment. The researchers used a scale to assess teacher performance on each dimension from 1 (Poor) to 5 (Excellent). Also, the mean score of both teachers for the experimental groups was higher than 4 (very good) for each lesson.

The control groups were instructed by two other teachers who used the traditional teaching methods involving vocabulary explanation, sentence creation and dialogue exercise. The teaching hours and content for the control and experimental groups were the same. The lessons of control group were observed and also video-taped to avoid the Hawthorne effect and the John Henry effect.

\subsection{Data Collection}

Quantitative and qualitative data were collected to answer the two research questions. These data include pre- and post-tests, classroom observations, interviews and the analysis of student assignments.

\subsubsection{Assessment of Writing Performance}

Student writing performance was assessed with the instrument designed by the researchers. The pre- and post-test writing tasks were based on the topics of ' $m y$ favourite sport' and 'my favourite food' for the four groups. The writing task was related to the topics the students learned about over the three months. Also, the two topics were closely related to the students' real experiences to provide more raw material for their writing.

The researchers used the framework from Rose and Martin as an assessment rubric [19], which contains 14 items covering four aspects: context, discourse, grammar and graphic features (see Appendix 1). On each item, student writing performance was assessed with a 3-point scale ranging from 0 to 2. If a student's writing met a criterion at the highest level, it scored 3. If there was no evidence for that criterion, it scored 0 . The minimum and maximum possible scores for students were 0 and 42, respectively. To check if each aspect referred to a common construct (the overall writing performance in the explanatory genre), a reliability test was performed. The alpha values were. 82 for the pre-test and.79 for the post-test. The correlations between four aspects were significant and positive. Thus the score of each aspect was aggregated for each student for further analysis.

Each piece of student writing was independently assessed by two research assistants with experience using R2L pedagogy and assessment criteria. The scorings of two raters were double-checked by one of the researchers for reliability and validity. A weighted Kappa test identified a between-rater agreement of $73 \%$ for the pre-test and $75 \%$ for the post-test, indicating a moderate level of consistency [40]. Then, the mean of the total scores assessed by two raters was calculated as the outcome of student writing performance.

\subsubsection{Interview}

Two teachers and 12 students with different Chinese levels from two experimental groups participated in interviews during and after the treatment. Their opinions on the R2L pedagogy and the challenges teachers encountered were explored during the interview. The audio was transcribed verbatim by a research assistant and double-checked by the researchers for accuracy.

\subsection{Data Analysis}

The pre-test and post-test data were analysed using SPSS 23.0. Descriptive statistics were used to illustrate the writing performance of students in the experimental and control groups before and after the intervention. An independent samples t-test was used to compare the baseline differences among the two groups in each cohort. To test hypothesis one, a paired sample t-test was used to see if students from all of the groups improved their writing with the three-month instruction period. To test hypothesis two, an analysis of covariance (ANCOVA) was applied to control pre-test values 
as a covariate for student post-test writing improvement between the two groups in each cohort after the intervention of R2L pedagogy.

For the qualitative data, a concept-driven approach was used in the analysis [41]. The first round of coding was open. Keywords and phrases were extracted from the descriptions of teachers and students. An inductive approach was adopted during the second round of coding, and the iterative words or phrases which evolved as themes were gradually generated at this stage. The advantages and challenges perceived by teachers and students were categorised. The teacher and student interviews were carried out in Cantonese and English, respectively. The teachers' interviews were transcribed verbatim into English by the researchers.

\section{Results}

For the first research question, both quantitative and qualitative data were used. The quantitative data are reported first, followed by qualitative data analysis. For the second research question with regard to the challenges faced by teachers, teacher interview data were mainly used and analysed.

\subsection{Initial Equivalence Between the Two Groups in Each Cohort}

Before the intervention, the initial equivalence between the experimental and control groups in the IIC and CFL cohorts were examined with an independent t-test. We found no significant difference between the two groups $[t(39)=1.04, p$ $=.30]$ in the IIC cohort and the CFL cohort $[t(60)=-1.70, p$ $=.10]$ (see Table 2).

Table 2. Comparison of Pre-test means, standard deviation of two groups in IIC and CFL cohort.

\begin{tabular}{llllll}
\hline IIC Cohort & & CFL cohort & & \\
\hline CG $(\mathbf{N}=\mathbf{2 1})$ & EG $(\mathbf{N}=\mathbf{2 0})$ & Sig & CG (N= 32) & EG (N = 30) & Sig \\
\hline M (SD) & M (SD) & & M (SD) & M (SD) & \\
$10.55(4.04)$ & $11.95(4.57)$ & 30 & $7.67(2.91)$ & $6.42(2.91)$ & 10 \\
\hline
\end{tabular}

Note. $\mathrm{CG}=$ Control group, $\mathrm{EG}=$ Experimental group.

\subsection{Improvement of Students' Writing in the Four Groups}

To test hypothesis one, a paired sample t-test was used to investigate if students from both the control and experimental groups improved their explanatory writing after the three-month instruction period. We found that both experimental groups from the IIC and CFL cohorts showed significant and moderate improvement, respectively $\left(t_{I I C}(29)=-7.20, p<.00 ; t_{C F L}(19)=\right.$ $-2.33, \mathrm{p}<.05)$. However, no significant difference was observed between the pre- and post-test for either control group $\left(t_{I I C}(20)=\right.$ $\left.1.41, p=.18 ; t_{C F L}(31)=-1.65, p=.11\right)($ see Table 3$)$.

Table 3. Comparison of pre- and post-test of writing performance for four groups.

\begin{tabular}{|c|c|c|c|c|c|c|c|c|c|c|c|}
\hline \multicolumn{6}{|c|}{ IIC cohort } & \multicolumn{6}{|c|}{ CFL cohort } \\
\hline \multicolumn{3}{|c|}{ EG $(N=20)$} & \multicolumn{3}{|c|}{ CG $(N=21)$} & \multicolumn{3}{|c|}{ EG $(\mathbf{N}=30)$} & \multicolumn{3}{|c|}{ CG $(\mathbf{N}=32)$} \\
\hline $\begin{array}{l}\text { Pre } \\
M(S D)\end{array}$ & $\begin{array}{l}\text { Post } \\
\text { M (SD) }\end{array}$ & Sig & $\begin{array}{l}\text { Pre } \\
M(\mathrm{SD})\end{array}$ & $\begin{array}{l}\text { Post } \\
\text { M (SD) }\end{array}$ & Sig & $\begin{array}{l}\text { Pre } \\
M(S D)\end{array}$ & $\begin{array}{l}\text { Post } \\
\text { M (SD) }\end{array}$ & Sig & $\begin{array}{l}\text { Pre } \\
M(S D)\end{array}$ & $\begin{array}{l}\text { Post } \\
\text { M (SD) }\end{array}$ & Sig \\
\hline $\begin{array}{l}11.95 \\
(4.57)\end{array}$ & $\begin{array}{l}14.67 \\
(4.90)\end{array}$ & $03 *$ & $\begin{array}{l}10.54 \\
(4.05)\end{array}$ & 9.10 & 18 & $\begin{array}{l}6.42 \\
(2.91)\end{array}$ & $\begin{array}{l}10.18 \\
(2.88)\end{array}$ & $00 * * *$ & $\begin{array}{l}7.67 \\
(2.92)\end{array}$ & $\begin{array}{l}8.78 \\
(4.51)\end{array}$ & 11 \\
\hline
\end{tabular}

Note. $\mathrm{CG}=$ Control group, $\mathrm{EG}=$ Experimental group. ${ }^{*} \mathrm{p}<.05 .{ }^{* *} \mathrm{p}<.01 .{ }^{* * *} \mathrm{p}<.001$.

\subsection{Effects of $R 2 L$}

To test hypothesis two, student writing performance in the post-test in the experimental and control groups was evaluated by analysis of covariance (ANCOVA). The pre-test was taken as the covariate to control for the possible influence of pre-test results and see whether the post-test score showed a statistical difference between the two groups in each cohort. The following result was obtained for the IIC cohort: $F(1,38)=15.21, p<.00, \eta_{\mathrm{P}}^{2}=.29$. This result demonstrated that the R2L pedagogy significantly improved the explanatory writing performance of students. The following results were obtained for the CFL cohort: $F(1,59)=$ $6.99, p<.05, \eta_{\mathrm{P}}^{2}=.11$ (see Table 4). This result suggested a moderate positive effect of $\mathrm{R} 2 \mathrm{~L}$ in enhancing the explanatory writing of students after the intervention.

Table 4. Adjusted means of the post-test, standard deviations, and analysis of covariance results of writing performance.

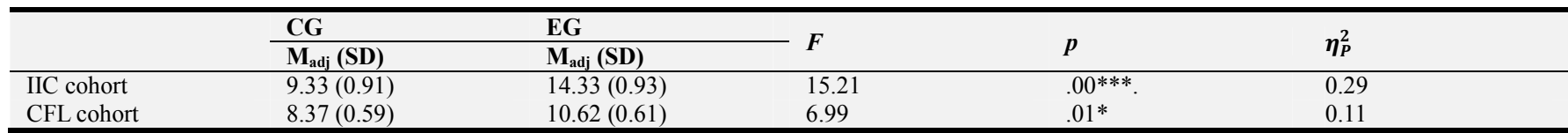

Note. $\mathrm{CG}=$ Control group, $\mathrm{EG}=$ Experimental group. ${ }^{*} \mathrm{p}<.05 .{ }^{* *} \mathrm{p}<.01$.

In addition to the results shown by the test scores, the interview data of the teachers and students also indicated the effectiveness of genre-based pedagogy for improving the Chinese writing of South Asian students. According to the IIC teacher, most students under R2L pedagogy properly structured their paragraphs with a clear writing thread. One student from the CFL experimental group also mentioned that 'the teacher always reminds us of the structure whenever we 
write. And with this, I really improve my writing'. Also, the interview data of their teacher revealed this opinion: 'Normally my students can only write one or two sentences to describe an event. But now these students know that they should describe things from various perspectives which make their composition more rich and logical. Apart from that, my students used to repetitively apply simple sentence structure in their composition, such as "He swims very fast".' Consequently, the students can apply words and phrases to depict more detail. With explicit teaching strategies, students have more time to understand and master text stages, sentence structure, phrases and words and then apply them to their writing, and joint construction provides more opportunities for students to integrate learning content with their prior knowledge and ultimately improve their writing.

In this study, the joint construction in $\mathrm{R} 2 \mathrm{~L}$ pedagogy enabled students to obtain additional support from their peers and teacher. The degree of student participation also considerably increased. As one CFL student said, 'If you are writing alone, sometimes you cannot understand what you are doing. But in joint construction, you'll have someone that you can ask any time for help'. The teachers' timely feedback can also effectively scaffold students and motivate their involvement in the co-construction of compositions. The IIC teacher offered the following comment:

Only a few good students were involved in my class before. But now, most students are encouraged to participate in co-construction. Normally, I group four students in a team, and they need to take responsibility for each part and co-write the whole story. Then, I will ask them to write their stories on the blackboard and let the other students give comments. Through this, all the students become actively engaged in my class.

With R2L, teacher can use effective instruction to ensure that students are familiar with the keywords, sentence structures and stages of the text. The teacher then allows students to apply these words and structures in their compositions, both individually and in co-constructions. Under the effective direction of a teacher, the students are given ample time to review and apply the language knowledge they acquire, thus helping them to improve their writing.

\subsection{Challenges of Using $R 2 L$}

Regarding the challenges of using R2L, this study found that knowledge of R2L pedagogy, limited teaching time and different learning needs are three main issues faced by Chinese teachers.

First, to implement R2L efficiently, teacher should possess a basic understanding of systemic functional linguistic theory, become familiar with the rationale and strategies of R2L and adapt their teaching content accordingly. Most reading materials selected for ethnic minority students in Hong Kong are short dialogues or paragraphs that describe daily scenarios in Hong Kong. These materials may not include the recommended stages emphasised in each genre. Hence, teachers should rewrite these paragraphs, prepare related materials to link the reading materials with students' prior experiences and design corresponding exercises to facilitate students' understanding. An IIC teacher stated that even after her three-month collaboration with the researchers in this study, she still needed continuous support to develop teaching materials. As she said, 'The textbooks we currently use are basically several pictures and paragraphs which are far from enough. These are not typical narrative texts for R2L. Thus, adapting textbooks will still be a great challenge if I continue to use R2L in my class.'

Second, the results suggested that some learning activities are characterised by a conflict between the requirement of full participation, on the one hand, and limited teaching time, on the other hand. Each round of R2L includes nearly nine stages for beginners and consumes much more time than traditional teaching; thus, teachers should resolve the conflict between enriched teaching activities and limited teaching time. As a CFL teacher stated, 'Joint construction is an effective activity to open the minds of my students and involve them actively. However, I have difficulty in reserving enough time to let them really finish the joint construction. Normally, a Chinese lesson is 40 minutes for one lesson, which is not enough for my 23 students to brainstorm and co-construct a composition. Thus, I have to let them finish the composition by themselves after school. This is contrary to the suggestions of R2L, but I have no choice'. For the ideal R2L pedagogy, learning activities are designed to encourage student motivation and to allow them to express themselves; however, several sessions of R2L may take much longer than a regular lesson in Hong Kong. Limited by this condition, teachers must revise the procedure or simply stop when class time is over.

Third, the various learning needs of students are also problematic for frontline teachers. As a CFL teacher said, 'Several of my students who excel in Chinese can easily understand what I mean, follow my instructions, and answer my questions, but those whose Chinese is below average experience difficulty in understanding the meaning of a single word, let alone understanding sentences or paragraphs. The differentiation is significant in my class. Sometimes I just keep on teaching no matter what'. Given the varying Chinese proficiency of students, teachers should consider different learning needs when preparing and implementing lessons. The empirical data shows that teachers experience difficulty in coping with this situation in practice.

In addition to differentiated levels, students' diverse backgrounds results in student differentiation. As an IIC teacher stated, 'Although our students have lived in Hong Kong for many years, several of them are not actually immersed in the local context. They only live in Pakistani or Nepalese circles, eat their traditional food, make friends with the same race and ignore local culture. For example, I taught an article that discussed the culture of food in Hong Kong. Several of my students had not been to a Cantonese restaurant, not even once. Therefore, teaching Chinese words for Cantonese food by just showing the pictures was difficult'. For some South Asian students who may not be fully integrated into Hong Kong society, it is hard for them to understand the words or phrases which are closely related to local context. Such knowledge requires that teachers dedicate time to describe, explain or illustrate the information. 
'Normally, if they have tasted local food, it is easier for me to teach them the Chinese name of the food. If not, I have to use more words to describe that food. This process may involve more new words that my students do not know. Describing and explaining always takes up much of my teaching time', the CFL teacher added.

\section{Discussion}

This study was designed to help ethnic minority students improve their Chinese writing performance. It was found that attending traditional Chinese lessons for several months cannot guarantee improvements in student writing. For example, for the students involved in this study, two control groups did not show any significant improvement in explanatory writing because teaching these groups only stresses vocabulary building and sentence structure. Although a sample explanatory text was provided for reading at the beginning of each unit, the knowledge specific to a genre, regarding stages and phases, is seldom discussed during instruction and is not demonstrated prior to students writing their own text. In contrast, with the three-month R2L intervention, student genre awareness, knowledge and genre writing performance significantly improved in the two experimental groups.

Darling-Hammond identified several common practices that can develop a comprehensive understanding among students [42]. These practices included the design of meaningful tasks to engage students, the assessment of strengths and needs, to improve curriculum and instruction, the scaffolding of successive steps and the various learning experiences that help students transition to a more proficient level of performance. These suggestions coincide with the features of the R2L pedagogy. The R2L pedagogy used in this study highlighted four key features, namely, stimulating and connecting the prior context knowledge of students with reference to reading materials; enhancing genre-specific knowledge, which includes lexicon, phrases and stages; constructing a support environment through engagement in learning activities; improving audience awareness and shaping purpose. In terms of the 'rhetorical reading of the genre exemplars' [9], the R2L pedagogy helped to 'enhance the explicit specification of the context and activate conventional phrases and discursive structure that are typical to the genre' [18].

This study showed that R2L can considerably enhance the Chinese composition proficiency of both medium- and low-performing students in the explanatory genre. This conclusion aligns with the outcomes of numerous empirical studies in the field of teaching English to speakers of other languages [7, 11, 18, 43-46]. The majority of the students in this study were born and raised in Hong Kong, but they are limited to learning Chinese in a school setting, constraining them from learning and using Chinese, especially in writing [47]. Rhetorical reading and related effective illustration are extremely important in the present study. These factors enable students to master the lexicon concerning the theme of a topic, to understand genre-related discourse, for example by marking conjunctions to establish logical connections and by understanding references and to form a framework or context that contains the appropriate field, tenor and mode. In R2L pedagogy, both high- and low-performing students are encouraged to master the construal and construction of texts and to expand their personal understanding toward creating a new context, so that they can 'develop their own personalized meaning in the target language' [48].

Furthermore, the students were grouped by school into different cohorts, and they received different curricula based on their Chinese language ability and previous test performance. At the beginning of this study, pre-test scores were roughly aligned with group differentiation. After the treatment, the students from the experimental group in the CFL cohort demonstrated a performance similar to those in the control group in the IIC cohort. The results showed that R2L significantly improved the language acquisition and composition skills of students with low Chinese proficiency. This study explicitly indicated that the potential of students to learn Chinese might be constrained by traditional teaching methods. According to Hyland, writing instruction should 'demystify prestigious forms of discourse' and 'facilitate their access to greater life changes' [12]. The outcomes of this study showed one or two steps which can effectively narrow the gap between high and low performers. Furthermore, this study suggested that the R2L pedagogy can help students with low Chinese proficiency to improve their academic performance. Such an improvement might lead to significant life changes of the students in the future.

This study indicated that teachers' comments can help students transfer the knowledge learned about genres to their logical thinking. Given limited teaching hours, students with limited ability to write correctly might fail to explicitly use genre knowledge in their composition. However, students who consciously used such knowledge in their oral presentations were able to reformat the structure. This finding showed that the students demonstrated not only an 'attention to the role of various rhetorical parameters, such as writing, reading, and purpose, in shaping a particular genre' [9], but also the ability to integrate such awareness into their own logical thinking. This result indicated that with R2L pedagogy, students can develop a keen awareness of the purpose of their writing and of the interaction between authors and audiences. In the process, students can become aware of their own logical thinking and reflect on how language is organised and used.

Although this study led to a highly positive outcome, it is worth noting that there were some challenges for frontline teachers in using R2L. Both teachers in the IIC and CFL cohorts pointed out the tremendous challenges surrounding curriculum design. Given these challenges, the development of teacher knowledge in terms of genre-based pedagogy should be the first issue addressed by researchers. Furthermore, the implementation of the R2L pedagogy in classroom teaching might represent another challenging task. According to Avalos, the core aim of professional development is to help teachers 'transform their knowledge into practice for the benefit of their students' [49]. This study showed that teachers can significantly improve the composition skills of students using the R2L pedagogy with 
the help of researchers in curriculum design. However, the question of how to improve the ability of teachers to design teaching materials and activities which meet different student learning needs merits further discussion and exploration.

\section{Conclusion}

R2L is an effective pedagogy in teaching English as a second language. This study extends the current understanding of R2L pedagogy by exploring its implementation in teaching Chinese as a second language among ethical minority students in Hong Kong. R2L pedagogy does not only improve writing performance, but it also enhances writing strategies and engagement. Notably, front-line teachers face difficulties in the effective implementation of $\mathrm{R} 2 \mathrm{~L}$ due to their constrained knowledge of systemic functional linguistic theory, R2L pedagogy, limited teaching time, and diverse student language levels and backgrounds. Identifying ways to effectively equip teachers with R2L and fit R2L into various teaching environments should be further investigated in future research.

\section{Limitations}

The empirical data indicated that the R2L pedagogy can significantly improve student writing. However, the findings should also be considered cautiously because the relatively small sample of students and teachers might restrict the power of statistical measures. Second, this research merely explored the effects of the R2L pedagogy with reference to explanatory genres over a relatively short period. Future study should be conducted to extend and include various genres using a longitudinal study as this may create a more holistic picture of the short- and long-term influences of the R2L pedagogy.

\section{Acknowledgements}

This work was supported by the Research Grants Council (RGC) competitive earmarked grant of Hong Kong Special Administration Region, China (Project No.: HKU 17605415).

\section{Appendix}

\section{Assessment Rubric Used in This Study}

Table A1. Assessment Rubric of writing (Rose \& Martin, 2012).

\begin{tabular}{|c|c|c|}
\hline \multicolumn{3}{|l|}{ CONTEXT } \\
\hline Staping & How appropriate and well-developed is the genre for the writing purpose? & $0-3$ \\
\hline Staging & $\begin{array}{l}\text { Does it go through appropriate stages, and how well is each stage developed? Label each stage in the text. } \\
\text { A well-organised text goes through a logical sequence of steps. Phases are the steps that a text goes through (within each stage!). }\end{array}$ & $0-3$ \\
\hline Phases & $\begin{array}{l}\text { Each phase may be a paragraph or a few sentence long. Identify and mark the phases in the text. How well organised is the } \\
\text { sequence of phases in the text? }\end{array}$ & $0-3$ \\
\hline Field & $\begin{array}{l}\text { How well does the writer understand and explain the field in factual texts, construct the plot, settings and characters in stories, or } \\
\text { describe the issues in arguments? }\end{array}$ & $0-3$ \\
\hline Tenor & How well does the writer engage the reader in stories, persuade in arguments, or objectively inform in factual texts? & $0-3$ \\
\hline Mode & How highly written is the language for the school stage? Is it too spoken? & $0-3$ \\
\hline \multicolumn{3}{|c|}{ DISCOURSE Discourse criteria should be marked in the text, to give an accurate picture. } \\
\hline Lexis & $\begin{array}{l}\text { Lexis is the word choices that writers use to build the field of a text. They are the content words, and the relations between these } \\
\text { lexical words from sentence to sentence. Mark the lexical words the writer uses. What are the writer's lexical resources? How well } \\
\text { is lexis used to construct the field? }\end{array}$ & $0-3$ \\
\hline Appraisal & $\begin{array}{l}\text { Appraisal is the word choices that writers use to evaluate. They include feelings, judgements of people, and appreciations of things, } \\
\text { and words that amplify and diminish. Mark the appraisal words the writer uses. What are the writer's appraisal resources? How } \\
\text { well is appraisal used to engage, persuade, evaluate? }\end{array}$ & $0-3$ \\
\hline Conjunction & $\begin{array}{l}\text { Conjunction is the logical relations between sentences, and within sentences. Mark the conjunctions the writer uses. Logical } \\
\text { relations may also be implicit. Is there a clear logical relation between all sentences? }\end{array}$ & $0-3$ \\
\hline Reference & $\begin{array}{l}\text { Reference is the words that are used to keep track of people and things through a text, including pronouns, articles, demonstratives } \\
\text { (this, that), comparatives (each, all, same, other). Mark all the reference words. Is it clear who or what is referred to in each sentence? }\end{array}$ & $0-3$ \\
\hline \multicolumn{3}{|c|}{ GRAMMAR You should make quick judgements about grammar and graphic criteria. } \\
\hline & $\begin{array}{l}\text { Are the grammatical conventions of written English used accurately? Is there an appropriate variety of sentence and word group } \\
\text { structures for the school stage, or is it too simple? }\end{array}$ & $0-3$ \\
\hline \multicolumn{3}{|c|}{ GRAPHIC FEATURES } \\
\hline Spelling & How accurately spelt are core words (frequent) and non-core words (less frequent)? & $0-3$ \\
\hline Punctuation & How appropriately and accurately is punctuation used? & $0-3$ \\
\hline Presentation & Are paragraphs used? How legible is the writing? Is the layout clear? Are illustrations/diagrams used appropriately? & $0-3$ \\
\hline
\end{tabular}

\section{References}

[1] Hyon, S. (2002). Genre and ESL reading: A classroom study. In A. M. John (Ed.), Genre in the classroom: Multiple perspectives (pp. 3-13). Mahwah, MJ: Lawrence Erlbaum.
[2] Johns, A. M. (2002). Genre and ESL/EFL composition instruction. In B. Kroll (Ed.), Exploring the dynamics of second language writing. New York: Cambridge University Press.

[3] Martin J. R. (2009). Genre and language learning: A special semiotic perspective. Linguistics and Education, 20 (1), 10-21. doi: 10. 1016/j.linged.2009. 01.003. 
[4] Halliday, M. A. K., \& Matthiessen, C. M. I. M. (1999). Construing experience through meaning: A language-based approach to cognition. New York: Continuum.

[5] Halliday, M. A. K. (1994). An introduction to functional grammar (2nd Ed.), London: Edward Arnold.

[6] Belcher, D. (2004). Trends in teaching English for specific purposes. Annual Review of Applied Linguistics, 24, 165-186. doi: $10.1017 / \mathrm{S} 026719050400008 \mathrm{X}$

[7] Byrnes, H. (2009). Emergent L2 German writing ability in a curricular context: A longitudinal study of grammatical metaphor. Linguistics and Education, 20 (1), 50-66. doi: 10. 1016/j.linged. 2009.01.005.

[8] Christie, F. (2002). Classroom discourse analysis: A functional perspective. London: Continuum.

[9] Cheng, A. (2008a). Analyzing genre exemplars in preparation for writing: The case of an L2 graduate student in ESP genre-based instructional framework of academic literacy. Applied Linguistics, 29 (1), 50-71. doi: 10.1093/applin/amm021.

[10] Cheng, A. (2008b). Individualized engagement with genre in academic literacy tasks. English for Specific Purposes, 27 (4), 387-411. doi: 10. 1016/j.esp.2008.05.001.

[11] Dovey, T. (2010). Facilitating writing from sources: A focus on both process and product. Journal of English for Academic Purposes, 9 (1), 45-60. doi: 10.1016/j.jeap. 2009.11.005.

[12] Hyland, K. (2007). Genre pedagogy: Language, literacy and L2 writing instruction. Journal of Second Language Writing, 16, 148-164. doi: 10.1016/j. jslw.2007.07.005.

[13] Johns, A. M. (2008). Genre awareness for the novice academic student: An ongoing quest. Language Teaching, 41 (2), 237-252. doi: $10.1017 / \mathrm{S} 0261444807004892$.

[14] Martin, J. R., \& Rose, D. (2008). Genre relations: Mapping culture. London: Equinox.

[15] Paltridge, B. (2004). Academic writing. Language Teaching, 37 (2), 87-105. doi: 10.1017/S0261444804002216.

[16] Shum, M. S. K., Tsung, L., Ki, W. W., \& Lam, M. (2010). Assessing Chinese: For teaching Chinese as a second language education and research. Volume II. Hong Kong: Centre for Advancement of Chinese Language Education and Research, Faculty of Education, the University of Hong Kong.

[17] Tardy, C. (2009). Building genre knowledge. West Lafayette, IN: Parlor Press.

[18] Yasuda, S. (2011). Genre-based tasks in foreign language writing: Developing writers' genre awareness, linguistic knowledge, and writing competence. Journal of Second Language Writing, 20 (2), 111-133. doi: 10.1016/j.jslw.2011.03.001

[19] Rose, D., \& Martin J. R. (2012). Learning to Write, Reading to learn: Genre. Knowledge and Pedagogy in the Sydney School. London: Equinox. doi: 10.1515/eujal-2017-0008.

[20] Martin, J. R. (1999). Mentoring semogenesis: 'genre-based' literacy pedagogy. In F. Christie (Ed.), Pedagogy and the shaping of consciousness: Linguistic and social processes (pp. 123-155). London: Continuum.

[21] Rose, D. (2011). Beyond literacy: Building an integrated pedagogic genre. Australian Journal of Language and Literacy, 34 (1), 81-97.

[22] Johns, A. M. (1997). Text, role and context: Developing academic literacies. New York: Cambridge University Press.

[23] McRae, D., Ainsworth, G., Cumming, J., Hughes, P., Mackay, T. Price, K., Rowland, M., Warhurst, J., Woods, D. \& Zbar, V. (2000). What has worked, and will again: the IESIP Strategic Results Projects. Canberra: Australian Curriculum Studies Association.

[24] Acevedo, C. (2010). A Report on School-based Action Research: Will the implementation of Reading to Learn in Stockholm Schools Accelerate Literacy Learning for Disadvantaged Students and Close the Achievement Gap? Stockholm: Multilingual Research Institute, Stockholm Education Administration

[25] Rose, D. (2018). Languages of Schooling: Embedding literacy learning with genre-based pedagogy. European Journal of Applied Linguistics, 6 (1), 31-57. doi: 10.1515/eujal-2017-0008.

[26] Huang, J. C. (2014). Learning to write for publication in English through genre-based pedagogy: A case in Taiwan. System, 45, 175-186. doi: 10. 1016/j. system.2014.05.010.

[27] Tuan, L. T. (2011). Teaching Writing through Genre-based Approach. Theory \& Practice in Language Studies, 1 (11), 1471-1478. doi: 10. 4304/tpls.1.11.1471-1478.

[28] Belcher, D. (1994). The apprenticeship model to advanced academic literacy: Graduate students and their mentors. English for Specific Purposes, 13 (1), 23-34. doi: 10.1016/0889-4906(94)90022-1.

[29] Cheng, A. (2006). Understanding learners and learning in ESP genre-based writing instruction. English for Specific Purposes, 25 (1), 76-89. doi: 10. 1016/j.esp.2005.07.002.

[30] Cheng, A. (2007). Transferring generic features and retexturing genre awareness: Understanding writing performance in the ESP genre-based literacy framework. English for Specific Purpose, 26 (3), 287-307. doi: 10.1016/j.esp.2006.12.002.

[31] Flowerdew, J. (2000). Discourse community, legitimate peripheral participation, and the nonnative-English-speaking scholar. TESOL Quarterly, 34 (1), 127-150. doi: 10.2307/3588099.

[32] Tardy, C. (2005). "It's like a story": Rhetorical knowledge development in advanced academic literacy. Journal of English for Academic Purposes, 4 (4), 325-338. doi: 10.1016/j.jeap.2005.07.005.

[33] Tardy, C. (2006). Researching first and second language genre learning: A comparative review and a look ahead. Journal of Second Language Writing, 15 (2), 79-101. doi: 10.1016/j.jslw.2006.04.003.

[34] Shum, M. S. K., Shi, D., \& Tai, C. P. (2016). The effectiveness of using 'reading to learn, learning to write' pedagogy in teaching Chinese to non-Chinese speaking students in Hong Kong. International Journal of Language Studies, 10 (3), 43-60.

[35] Shum, M. S. K., Tai, C. P., \& Shi, D. (2018). Using 'Reading to Learn' (R2L) pedagogy to teach discussion genre to non-Chinese-speaking students in Hong Kong. International Journal of Bilingual Education and Bilingualism, 21 (2), 237-247. doi: 10.1080/13670050.2016.1159653. 
[36] Legislative Council (2018). Replies to Initial Written Questions Raised by Finance Committee Members in Examining the Estimates of Expenditure 2017-18. Hong Kong: Finance Committee, Legislative Council.

[37] Census and Statistics Department (2017). Hong Kong 2016 Population By-census- Thematic Report: Ethnic Minorities. Hong Kong: Census and Statistics Department, Hong Kong Special Administration Region.

[38] Troia, G. A. (2006). Writing instruction for students with learning disabilities. In C. A. MacArthur, S. Graham, \& J. Fitzgerald (Eds.), Handbook of writing research (pp. 324-336). New York: The Guilford Press.

[39] Zhang, Q. Y., Tsung, L., Cruickshank, K., Ki, W. W. \& Shum, M. S. K. (2011). South Asian students' educational experience and attainment: Learning Chinese as a second/ additional language in Hong Kong. In L. Tsung, \& K. Cruickshank (Eds.), Teaching and learning Chinese as global contexts (pp. 63-80). London: Continuum.

[40] Beach, R. (1992). Experimental and descriptive research methods in composition. In G. Kirsch \& P. A. Sullivan (Eds.), Methods and methodology in composition research. Carbondale, IL: Southern Illinois UP.

[41] Kvale, S., \& Brinkmann, S. (2009). Interviews: Learning the craft of qualitative research. California, US: SAGE.

[42] Darling-Hammond, L. (2016). Research on teaching and teacher education and its influences on policy and practice. Educational Researcher, 45 (2), 83-91. doi: 10.3102/0013189X16639597.
[43] Crane, C. (2006). Modeling a genre-based foreign language curriculum: Staging advanced L2 learning. In H. Byrnes (Ed.), Advanced language learning: The contribution of Halliday and Vygotsky (pp. 227-245). London: Continuum.

[44] Caffarel, A. (2006). Learning advanced French through SFL: Learning SFL in French. In H. Byrnes (Ed.), Advanced language learning: The contribution of Halliday and Vygotsky (pp. 204-224). London: Continuum.

[45] Ryshina-Pankova, M. V. (2006). Creating textual worlds in advanced learning writing: The role of complex theme. In $\mathrm{H}$. Byrnes (Ed.), Advanced language learning: The contribution of Halliday and Vygotsky (pp. 164-183). London: Continuum.

[46] Teruya, K. (2006). Grammar as a resource for the construction of language logic for advanced language learning in Japanese. In H. Byrnes (Ed.), Advanced language learning: The contribution of Halliday and Vygotsky (pp. 109-133). London: Continuum. doi: 10.1016/j.linged.2009. 01.008.

[47] Shum, M. S., Gao, F., Tsung, L., \& Ki, W. W. (2011). South Asian students' Chinese language learning in Hong Kong: Motivations and strategies. Journal of Multilingual and Multicultural Development, 32 (3), 285-297.

[48] Teruya, K. (2009). Grammar as a gateway into discourse: A systemic functional approach to subject, theme, and logic. Linguistics and Education, 20 (1), 67-79. doi: 10.1016/j.linged.2009.01.008.

[49] Avalos, B. (2011). Teacher professional development in teaching and teacher education over ten years. Teaching and teacher education, 27 (1), 10-20. doi: 10.1016/j.tate.2010.08.007. 